ARTIGO ORIGINAL

\title{
Percepções docentes a partir de uma intervenção pedagógica esportiva
}

\section{Teaching perceptions from a sporty pedagogical intervention}

Patrícia da Rosa Louzada da Silva, Patricia Machado da Silva, Vivian Hernandez Botelho, Franciéle da Silva Ribeiro, Eraldo dos Santos Pinheiro

Universidade Federal de Pelotas (UFPel), Pelotas/RS, Brasil

\section{HISTÓRICO DO ARTIGO}

Recebido: 17 março 2020

Revisado: 05 agosto 2020

Aprovado: 02 setembro 2020

\section{PALAVRAS-CHAVE:}

Esportes; Educação; Ensino; Estudantes.

\section{KEYWORDS:}

Sports; Education; Teaching; Students.

\section{RESUMO}

OBJETIVO: O estudo buscou verificar a percepção das professoras do currículo de uma escola pública da rede estadual de Pelotas (RS) sobre o desempenho motor, cognitivo e comportamental das suas turmas, a partir da intervenção pedagógica do projeto de extensão Jogando para Aprender (JPA).

MÉTODOS: Participaram da pesquisa duas professoras, responsáveis pelo primeiro e segundo ano do Ensino Fundamental. Para a coleta das informações foram utilizadas entrevistas do tipo semiestruturada, aplicadas antes e após a realização da intervenção. Para analisar as informações nos aproximamos da técnica de Bardin, realizando a análise de maneira cronológica.

RESULTADOS: A percepção da evolução dos alunos, os quais passaram a ser mais organizados, cooperativos e menos agressivos.

CONCLUSÃO: A investigação se mostrou importante, tanto porque possibilita a aquisição de informações pertinentes a futuras intervenções, como também expressa uma relação positiva da ampliação de vivências motoras com aspectos comportamentais dos alunos participantes.

\section{ABSTRACT}

OBJECTIVE: This study seek to verify the perception of curriculum teachers of a state public school about the motor, cognitive and behavioral performance of their classes from the pedagogical intervention of the extension project.

METHODS: Two teachers participated in the research, responsible for the first and second years of elementary school. To collect the information, semi-structured interviews were used, applied before and after the intervention. To analyze the information, the Bardin techinic was used, performing the analysis in a chronological way.

RESULTS: The perception of the students' evolution, who showed to be more organized, cooperative and less aggressive.

CONCLUSION: The investigation proved to be important both, for the acquisition of information pertinent to future interventions, as well as expressing the positive influence of the expansion of motor experiences with behavioral aspects of the participating students. 


\section{INTRODUÇÃO}

A Lei de Diretrizes e Bases da Educação Nacional, Lei n.으 9.394/96 (BRASIL, 1996), em relação às séries iniciais do ensino básico, estabelece, em seu Artigo $26, \S 3^{\circ}$, que "[a] educação física, integrada à proposta pedagógica da escola, é componente curricular obrigatório da educação básica". Entretanto, a Resolução no 7/2010, que fixa as Diretrizes Curriculares Nacionais para o Ensino Fundamental (BRASIL, 2010), possibilita que o componente curricular seja ministrado por um professor sem formação específica de Licenciatura em Educação Física.

Art. 31 - Do 1음 5o ano do Ensino Fundamental, os componentes curriculares Educação Física e Arte poderão estar a cargo do professor de referência da turma, aquele com o qual os alunos permanecem a maior parte do período escolar, ou de professores licenciados nos respectivos componentes (BRASIL, 2010).

Desta maneira, municípios e estados adequam conforme seus interesses a presença de tais profissionais, sendo que na maioria dos casos os conteúdos da área são ministrados pelos próprios professores do currículo, com formação em Pedagogia, Magistério ou Normal. Desta forma, a responsabilidade pelos conteúdos específicos da Educação Física (EF) a serem desenvolvidos pelos professores do currículo causa insegurança, pois "os professores muitas vezes não se sentem preparados e motivados para trabalhar com a disciplina de EF" (DARIDO; RANGEL, 2005 , p. 56), por diversos motivos, dentre eles a falta de formação específica.

No Rio Grande do Sul, a interpretação da Lei permite que as escolas do Estado não possuam professores com formação em EF para atuarem na educação infantil e nos anos iniciais do Ensino Fundamental. Portanto, a EF ocorre de acordo com a disponibilidade dos professores do currículo para planejar e orientar práticas corporais.

Por outro lado, desde o fim dos anos 1970 e início dos 1980, surgiram diversas abordagens pedagógicas da EF que, em parte ou exclusivamente, discutem a EF na educação infantil e nos anos iniciais. Essas abordagens sustentam certos princípios norteadores e visam não só estabelecer a identidade da EF, mas ocupam-se também da operacionalização dos conteúdos para essas faixas etárias. Dentre as principais concepções, merecem destaque a educação psicomotora (LE BOULCH, 1987), a abordagem desenvolvimentista (TANI et al., 1988) e a construtivista (FREIRE, 1991). Esta última tem um capítulo abordando a pedagogia do movimento na 2 a infância, em que trata da EF como uma educação de corpo inteiro. Para Freire, não basta aprender habilidades motoras, mas também é necessário adquirir as intelectuais: "corpo e mente devem ser entendidos como componentes que integram um único organismo" (FREIRE, 1991, p. 13).

Tratando-se do ensino do esporte, Greco e Breda (1998), por meio do método da Iniciação Esportiva Universal (IEU), propõem um ensino que respeita o desenvolvimento da criança, indicando aos professores como tratar pedagogicamente de cada fase. Voser, Giusti e Azevedo Júnior (2016, p. 24), ao se referirem à IEU, apontam que "a criança é tratada como criança", no sentido de buscar o trabalho das capacidades coordenativas diretamente ligadas aos aspectos motores/técnicos e cognitivos/táticos por meio do brincar e do jogar. O método de ensino do esporte exposto é corroborado quando em sua intencionalidade aplica- -se o princípio da totalidade, ao considerar o ser humano como um todo, indissociável em sua prática as emoções das ações. Nesse sentido, as práticas corporais esportivas orientadas pela IEU propiciam interações entre os pares, culminando em um processo de autoconhecimento, superação, aprendizado de atitudes favoráveis de respeito e apoio aos colegas. Desse modo, potencializa-se o convívio e, consequentemente, melhoram os aspectos atitudinais, diretamente ligados aos comportamentais (BROTTO; ROSSETTO, 2017).

Compreende-se, portanto, que um ensino qualificado do esporte requer bases pedagógicas claras para orientar o aprendizado de crianças e adolescentes, garantindo que sejam concomitantemente desenvolvidos os aspectos motores/técnicos, cognitivos/táticos e atitudinais/comportamentais. Assim, é indubitável a necessidade de professores com formação específica na área de EF, e é compreensível que os professores do currículo sintam dificuldades, devido ao fato de sua formação inicial não os capacitar para o planejamento e o desenvolvimento de aulas de ensino do esporte (NORA; SAWITZKI, 2014).

Neste sentido, a implementação de parcerias entre a Universidade e Secretarias de Educação pareceu ser uma alternativa de apoio às escolas, embora não resolva o problema da ausência do professor de EF nos anos iniciais, possibilitaria trocas de experiências. Deste modo, a Escola Superior de Educação Física da Universidade Federal de Pelotas (ESEF/UFPel), por meio de seu Laboratório de Estudos em Esporte Coletivo (LEECOL), com interesse em aproximar os estudos do laboratório a aplicação prática no ambiente escolar, buscou parceria com uma escola estadual. Destaca-se que, durante o período desta investigação, a escola não contava com professores de EF para os anos iniciais do Ensino Fundamental, assim como as demais escolas estaduais da cidade. Cientes da impossibilidade de modificar um cenário que é de responsabilidade do estado e de suas Secretarias em manter professores de EF na Educação Básica, em especial na Educação Infantil e Fundamental I, mas na tentativa de colaborar com os professores do currículo, ofertando aos alunos práticas corporais esportivas, promoveu-se o projeto denominado "Jogando Para Aprender" (JPA), que será contextualizado detalhadamente nos métodos (PINHEIRO et al., 2018; PINHEIRO et al., 2020).

Nesse sentido, o presente estudo buscou verificar a percepção das professoras do currículo de uma escola pública da rede estadual de Pelotas sobre o desempenho motor, cognitivo e comportamental das suas turmas, a partir da intervenção pedagógica do projeto de extensão JPA.

\section{MÉTODOS}

\section{Contextualizando o objeto de pesquisa}

A escola estadual parceira foi fundada em 1971 e anualmente atende cerca de 500 escolares entre Ensino Fundamental e Médio. A escola fica localizada em uma região nobre da cidade e, de acordo com a direção, a comunidade escolar é composta por moradores de diversas localidades e vários alunos moram distantes, além de passarem por dificuldades sociais.

A escola parceira foi escolhida pela proximidade com a ESEF/ UFPel, por não possuir professores de EF nos anos iniciais do Ensino Fundamental durante o período de intervenção pedagógica (IP), e porque a direção mostrou-se receptiva a colaborar com a realização do projeto de extensão. 
O projeto de extensão JPA tem atuação desde 2016 em uma escola pública estadual. O JPA está presente na escola estudada desde 2017, em 2018 atuavam no projeto seis acadêmicos do curso de Licenciatura em EF (graduandos de diferentes semestres da graduação), duas estudantes do Programa de Pós-Graduação em EF da UFPel e um professor coordenador. $O$ JPA atende, aproximadamente, 120 escolares anualmente, do 10 ao 5 o ano, com aulas de 45 a 50 minutos, duas vezes por semana. Cada turma tem o seu planejamento, que é elaborado pelos acadêmicos e pós-graduandos de EF e executado pelos graduandos.

Para realização da IP, no segundo semestre de 2018, foram atendidas 23 crianças de seis a oito anos, sendo 15 matriculadas no primeiro ano e oito no segundo ano do Ensino Fundamental, nas dependências da escola parceira, totalizando 16 encontros presenciais, com atividades realizadas em conjunto pelas turmas.

A base teórico-metodológica do JPA durante a IP foi a IEU, proposta por Greco e Benda (1998), a qual tem apresentado relevante para desenvolver e aperfeiçoar a coordenação motora de crianças em idades escolares. Sendo definida pelos autores como

[u]ma alternativa pedagógica importante para a faixa etária entre 4-6 e 1112 anos. Nestas faixas etárias, o jogo deve ser um elemento didático-pedagógico que deverá ser oferecido, conforme as características evolutivas da criança, especialmente no que se refere à sua maturidade, evolução psicoló gica e cognitivo-social. Como exemplo, crianças de 6-8 anos devem trabalhar com jogos de perseguição, estafetas, jogos de relevos, dentre outros. (GRECO; BENDA; RIBAS, 2007, p. 68).

Nesse sentido, o método da IEU serve como sinalizador para as atividades guiadas do JPA. Os parâmetros utilizados para o planejamento e a realização do trabalho são voltados à aprendi- zagem motora, sem a especificidade de uma modalidade esportiva, tentando oportunizar diferentes experiências para que os conhecimentos fossem ampliados.

De acordo os pressupostos sugeridos pela IEU e o que se indica à faixa etária do público alvo estudado, o foco do JPA foi o ensino e o aprendizado motor, fortemente atrelados ao ensinoaprendizagem-treinamento das capacidades coordenativas.

A fórmula para o ensino-aprendizagem-treinamento das capacidades coordenativas consiste em se apresentar habilidades simples (com/sem bola), relacioná-las com os elementos de pressão da percepção, dos sentidos que procedem à recepção da informação, e que a resposta motora a ser realizada seja colocada também em situação de pressão semelhante às que acontecem nas modalidades esportivas (GRECO, 2012, p. 157).

Na parte inicial, de no máximo dez minutos, os escolares eram guiados a praticar um aquecimento. A parte principal, com tempo máximo de 30 minutos, era composta por circuitos motores, jogos de perseguição e estafetas. Com a finalidade de desenvolver as capacidades coordenativas (KRÖGER; ROTH, 2002). Foram sempre utilizados como base a presença de dois parâmetros de pressão por aula. O Quadro 1 exemplifica os quatro principais modelos de aula.

A parte final de cada aula, entre cinco e dez minutos, era destinada à roda de conversa sobre o aprendizado e os objetivos alcançados. Nesse momento, os alunos eram questionados a respeito do aprendizado, dos sentimentos sobre a aula, da importância das ações em conjunto, de serem cooperativos e demonstrarem apoio uns aos outros. Eram indagados também, se percebiam ser possível brincar por muito mais tempo, quando não ocorriam brigas entre eles. Para finalizar o momento, eram destacados pontos positivos e favoráveis da aula.

Quadro 1. Estrutura da intervenção pedagógica do projeto de extensão Jogando para Aprender (JPA), 2018.

\begin{tabular}{|c|c|c|c|}
\hline $\begin{array}{c}\text { Modelos } \\
\text { de aula }\end{array}$ & Parâmetros de pressão & Parte inicial - Aquecimento & Parte principal - Atividades \\
\hline 01 & Precisão e tempo & $\begin{array}{l}\text { Deslocamento ocupando espaços } \\
\text { demarcados no chão. }\end{array}$ & $\begin{array}{l}\text { 1- Em colunas, passar a bola de um para o outro, pelo lado direito e esquerdo, por } \\
\text { cima da cabeça, entre as pernas. } \\
\text { 2- Em trios, lançar e receber a bola entre o arco. } \\
\text { 3- Correr sobre os arcos no chão e arremessar tentando acertar diferentes alvos. }\end{array}$ \\
\hline 02 & Complexidade e tempo & Brincadeira de pega-pega. & $\begin{array}{l}\text { 1- Condução de bola pela quadra com a mão e depois com o pé. } \\
\text { 2- Percorrer percurso estabelecido, superando obstáculos: saltar e rolar seguido de } \\
\text { picos de corrida. } \\
\text { 3- Corrida lateral, superando obstáculos dispostos no chão. }\end{array}$ \\
\hline 03 & Complexidade e carga & Brincadeira do nunca 3. & $\begin{array}{l}\text { 1- Conduzir uma bola de um cone até o outro e, após, rolar sobre um colchonete. } \\
\text { 2- Escolar deve ficar entre dois cones, tocar no cone esquerdo, após no direito e de- } \\
\text { pois fazer o passe com bola de futsal para o colega que estará à frente, que deverá } \\
\text { fazer o mesmo. } \\
\text { 3- Em duplas, passar a bola com a mão para o colega, que antes de receber deve fazer } \\
\text { um giro com o corpo.4- Carrinho humano. Carregar o colega segurando suas pernas } \\
\text { de um ponto a outro. }\end{array}$ \\
\hline 04 & Organização e variabilidade & $\begin{array}{l}\text { Escolares correndo em círculo, } \\
\text { tentando impedir que a pessoa de } \\
\text { fora entre. }\end{array}$ & $\begin{array}{l}\text { 1- Em duplas, quicar uma bola cada um. Após, é introduzida uma terceira bola, que } \\
\text { deve ser passada de um colega para o outro. Ficando, em momentos, um aluno com } \\
\text { duas bolas. } \\
\text { 2- Caminhar com diferentes materiais sobre o corpo, um e dois, equilibrando-os. } \\
\text { 3- Circuito: Rastejar sobre colchonetes, rolar, chutar uma bola no gol, caminhar equi- } \\
\text { librando bola de tênis sobre a raquete, jogar a bola para cima e bater palma antes de } \\
\text { segurar novamente. }\end{array}$ \\
\hline
\end{tabular}

Fonte: Elaborado pelos autores, 2019 


\section{Caminhos percorridos para construção do estudo}

Este estudo é de caráter descritivo, de delineamento ex-post facto, definida assim a investigação em que são feitas inferências sobre as relações entre as variáveis, já que os pesquisadores não possuem controle sobre as mesmas (GIL, 2008).

Para compor o estudo, foram convidadas duas professoras do currículo, regentes das turmas em que a IP do projeto de extensão JPA ocorreu. Cabe destacar que a quantidade de duas participantes está relacionada ao número de turmas com as quais ocorreram as intervenções. No entanto, como não há o interesse de generalizar os relatos e os conhecimentos desenvolvidos durante o processo, mas retratar o que ocorreu naquele contexto específico, não há preocupação com relação à representatividade da amostra.

A coleta de informações deu-se por meio da entrevista do tipo semiestruturada que, para Triviños (1995), é um instrumento que parte de questionamentos propostos pelo pesquisador, mas permite ao informante manter a linha de seu pensamento, de modo espontâneo, sem perder o foco principal do estudo.

Para direcionar as entrevistas semiestruturadas, foram utilizados dois roteiros, com cinco questões cada. Os questionários foram aplicados em momentos distintos da investigação, atendendo objetivos diferentes. O primeiro, aplicado na fase que antecedeu a realização da IP do JPA foi direcionado a conhecer as turmas, aspectos sociais e, a partir das questões investigativas, identificar como as professoras do currículo percebiam as suas turmas em relação a aspectos motores, cognitivos e comportamentais.

No segundo momento de investigação, o qual ocorreu após a IP do JPA, as questões investigativas buscaram identificar se as professoras percebiam avanços em relação aos aspectos motores, cognitivos e comportamentais, em caso afirmativo, associavam-se à IP do JPA. A seguir a questão demonstrativa:

Professora, após a IP do JPA, você percebeu modificações com relação ao aspecto motor, cognitivo e comportamental da turma? Ocorreram avanços? Se sim, quais? Cite exemplos e, ainda, se na sua percepção tais avanços estão associados à experiência dos mesmos com a intervenção do JPA?

A aplicação da entrevista semiestruturada foi realizada na própria escola, por uma pesquisadora experiente, em ambiente restrito e sem interferência de outras pessoas, face a face, com gravação de áudio em aparelho celular da marca Samsung modelo J7. Posteriormente, foram transcritas pelos pesquisadores e devolvidas às entrevistadas, para que validassem o conteúdo. Tal prática se sustenta na indicação de Neto e Triviños (2017), quando reforça a importância de transcrever e apresentar o material para leitura e aprovação do participante.

Para analisar as informações nos aproximamos da técnica de Bardin (2011), realizando a análise de maneira cronológica. Sendo desenvolvida a partir de três fases: na pré-análise, procuramos realizar a leitura das transcrições, levando em consideração as duas categorias estabelecidas a priori (características gerais da turma e percepções com relação aos avanços motores, cognitivos e comportamentais); na análise do material, refizemos a leitura das transcrições de maneira a permitir a emersão das categorias. Por fim, tratamos os resultados realizando inferências e interpretações, na medida em que buscamos referenciais que se aproximassem do exposto pelas professoras, a fim de formular e embasar nossas discussões (BARDIN, 2011).
O caráter ético dos procedimentos da pesquisa foi assegurado pela aceitação das professoras em participarem do estudo e ao autorizarem a divulgação dos resultados, após terem lido e assinado o Termo de Consentimento Livre e Esclarecido. Este estudo foi aprovado pelo comitê de ética da Escola Superior de Educação Física da Universidade Federal de Pelotas (Parecer $N^{\circ}$. 2.955.536).

\section{RESULTADOS}

As participantes deste estudo são professoras efetivas do Estado do Rio Grande do Sul e estão formadas há mais de dez anos em Pedagogia. Ambas foram receptivas, tanto para o início da IP, permitindo a participação de suas turmas no projeto, quanto para outros procedimentos que necessitamos, tais como: aplicação das entrevistas, leitura e validação das transcrições e nos diálogos, realizando ajustes necessários ao longo do trabalho desenvolvido. Destacamos que o sigilo quanto à identidade das professoras será mantido, dessa forma iremos referenciar suas falas identificando-as como Professora, seguido dos números 1 e 2, sendo que 1 se refere à professora do primeiro ano, e 2 à professora do segundo ano.

\section{Percepção das professoras do currículo sobre as características das turmas pré IP JPA}

Na pré-análise, buscamos compreender quais as percepções das professoras quanto às características gerais das duas turmas e percebemos que se tratavam realidades distintas. Utilizamos a seguinte pergunta: "De modo geral, como é a turma? Com relação ao comportamento dos alunos, existe algum com maior dificuldade? Quem?".

Enquanto a turma de primeiro ano se destacava pelo bom relacionamento entre os escolares, e foi descrita pela Professora 1 como: "uma turma fácil de lidar", "com boa participação dos pais", grifando a facilidade de dialogar com os responsáveis e como isso refletia no melhor aprendizado dos alunos. A Professora 2 grifou a heterogeneidade de sua turma, os constantes conflitos e disputas no relacionamento entre seus alunos e a dificuldade em conversar com os responsáveis, o que, segundo ela, tornava o trabalho docente muito lento e conturbado.

\section{Uma coisa que é complicada: os pais são pouco participativos. Eu tenho dois alunos que vêm de van, não consigo conversar com os responsáveis, até nas reuniões eles vêm, mas aquele encontro cotidiano, que eu particularmente gosto, não tem. (PROFESSORA 2, 2018)}

Conforme descreve Brandão (2016), a instituição escolar é o espaço em que os alunos têm a primeira interação social externa ao ambiente familiar. A relação entre família e escola é de fundamental importância na vida dos indivíduos, visto que com essa complementação há uma melhora no aprendizado dos escolares e maior segurança na relação entre pais e professores. Por consequência, a atuação dos familiares na vida das crianças é importante para o desenvolvimento delas. Quando as famílias possuem um conhecimento maior da vida escolar dos filhos e se envolvem com a educação, os resultados são refletidos na vida acadêmica dos alunos (SEITSINGER et al., 2008). Essa asserção é corroborada pela Professora 1 ao referir-se à influência que a família tem na vida dos alunos. 
Essa turma é uma turma boa. Este ano que eu peguei assim, a maior parte deles tem uma boa estrutura familiar e, com exceção de dois, o resto tem boas condições financeiras. Eu digo boas porque em escola pública tu pega crianças de baixa renda que vem com fome para escola. (PROFESSORA 1, 2018)

Já na turma de segundo ano, conforme mencionado pela Professora 2, a rivalidade entre dois alunos reforçava a dificuldade de relacionamento entre a turma, retardando o andamento das aulas. Os colegas ficavam incomodados com comportamento dos dois e tudo, inclusive o ensino, ficava prejudicado. Os alunos utilizavam muitas vezes da violência verbal, do constrangimento, desrespeitando os colegas. Nesse sentido, Salles et al. (2014) afirmam que quando os atos se tornam repetitivos, passam a ser considerados normais, o que contribui para atitudes de agressão.

Ao conhecer tal característica da turma, e em especial desses dois alunos, houve uma persistência dos professores do JPA para que os fatos não tornassem a se repetir. $O$ trabalho ao longo da intervenção foi árduo, de forma a demonstrar a importância de cada um deles e de como, em qualquer brincadeira ou jogo, é importante ter com quem e para quem jogar. Freire (1997, p. 21) destaca que "[s] e o contexto foi significativo para a criança, o jogo, como qualquer outro recurso pedagógico, tem consequências importantes em seu desenvolvimento". Na mesma linha, assevera que as relações estabelecidas através das brincadeiras permitem com que a criança forme seu conhecimento do mundo (FREIRE, 1997, p. 19).

\section{Diálogo sobre a importância da EF na escola e as expectativas das professoras do currículo quanto à realização do JPA}

A escola foco do estudo tem a EF, como um dos componentes curriculares obrigatórios, conforme a LDB 9.394/96. No entanto, a presença do professor de EF até o quinto ano do Ensino Fundamental, no momento dessa investigação, não ocorria. Com isso, a insegurança apontada no estudo de Darido e Rangel (2005), com relação aos professores do currículo em trabalhar com a EF na escola também foi identificada no presente estudo, quando uma das participantes manifestou:

Olhar o trabalho de vocês é totalmente diferente do que a gente tenta fazer pois a gente tenta, até leva para o pátio, pracinha, mas não é um trabalho direcionado, nem sabemos ao certo como fazer. (PROFESSORA 1, 2018)

A partir das falas, é possível inferir que as professoras se sentem pouco preparadas para ministrar aulas de EF. Ao mesmo tempo, reconhecem a importância de um profissional qualificado, alguém que, a partir do movimento, administre uma possível intervenção capaz de interferir nos aspectos cognitivos, motores e comportamentais, através de uma prática direcionada, com sentido, objetivos e metodologia adequados. Além disso, demonstram a percepção sobre a importância do brincar e verbalizam sua própria limitação no processo de conferir relevância a essa atividade na vida dos alunos e, por essas razões, mantinham expectativa positiva em relação à intervenção do JPA. Segundo uma delas, esperavam que o JPA seria "uma coisa ótima para eles, pois nós não somos devidamente formadas para trabalhar com os conteúdos da EF. Nós trabalhamos do nosso jeito, pensando nas brincadeiras e tal" (PROFESSORA 2, 2018).

Além da expectativa favorável, as professoras demonstraram aceitação da intervenção, pois sabem da importância de profissionais capacitados na escola para trabalhar com a EF e compreendem as lacunas do curso de Pedagogia, no sentido de prepará-las para intervir com os conteúdos específicos da EF. Os benefícios da prática esportiva guiada e direcionadas ao desenvolvimento das crianças aprimoram as competências físicas e cognitivas, além de beneficiar relações interpessoais e aspectos socioemocionais dos participantes (VIANA-MEIRELES et al., 2020).

No presente estudo, a aplicação da intervenção almejava um modelo de ensino do esporte que aprimorasse as capacidades coordenativas das crianças, baseados na perspectiva de brincadeiras e do jogo possível, ou seja, aquele composto por exigências motora/técnica e cognitivo/tática, de acordo com a faixa etária (VOSER; GIUSTI; AZEVEDO JÚNIOR, 2016).

\section{Percepção das professoras do currículo sobre as características das turmas após a IP do JPA}

A entrevista realizada após o desenvolvimento do projeto JPA demonstra a percepção de avanços, no sentido da evolução dos alunos, os quais passaram a ser mais organizados, cooperativos e menos agressivos. Foi proposta a seguinte questão: "No decorrer do projeto, você percebeu alguma mudança nos alunos, em relação ao comportamento, ao aprendizado, ao convívio entre eles, à organização?". A Professora 1 mencionou, "Já estou vendo diferença, os observo mais amigos uns dos outros, porque eu acho que os jogos trabalham esta coisa de cooperação, de precisar do outro".

Os alunos dos anos iniciais, têm características mais egocêntricas, porém Piaget (1994) indica o estímulo da cooperação desde cedo, a partir de duplas e trios até se chegar a grupos maiores. Portanto, a prática de atividades cooperativas é propulsora a uma formação mais colaborativa e humana (NETO, 2015).

Ademais, outra especificidade da turma de $1^{\circ}$ ano foi a participação do aluno diagnosticado com Transtorno do Espectro do Autismo, pois ele participou da IP, superou sua insegurança e nem as especificidades da deficiência o afastaram de ter um relacionamento positivo com os professores do JPA. Assim percebeu a Professora 1:

Seu aprendizado surpreendeu a todos [...]. Pois no começo era inseguro, precisava ser unicamente uma determinada professora do projeto a buscá-lo, do contrário demonstrava insegurança, mas foi evoluindo e se tornando cada vez mais participativo e familiarizado com os demais professores de Educação Física do projeto. (PROFESSORA 1, 2018)

Na turma do $2^{\circ}$ ano concentravam-se as maiores dificuldades de relacionamento. A percepção da Professora 2 indica que os casos de agressões diminuíram e os alunos que mais problematizavam e tinham constantes desavenças, passaram até a brincar no recreio.

A atitude deles na sala de aula mudou, mudou muito, não te digo assim que ficaram cem por cento, né?, mas parece que eles ficaram mais amigos, sabe?... mais companheiros. Aquelas brigas que tinham até mesmo entre o $\mathrm{H}$ e o D, que eu comentava, continua alguma coisa, mas já diminuiu bastante, eu já vejo que no recreio eles brincam juntos. (PROFESSORA 2, 2018)

Certamente as desavenças não foram sanadas em sua totalidade, mas não podemos subestimar a influência do contexto cultural e social em que vivem. Conforme Kanul e Ramírez (2005), as crianças tendem a reproduzir, ao longo de sua vida, comportamentos que aprendem, e a agressão é um deles. 
Além disso, uma das professoras grifou sua preocupação com a falta do brincar de seus alunos e com as consequências disso.

A maioria desses alunos aqui, em casa, não faz nada. Eles relatam que é só videogame, na frente da TV, eles não brincam. Eu trabalhei com eles o pular corda e fiquei impressionada, numa turma de dezesseis, apenas dois sabiam pular corda... (PROFESSORA 1, 2018)

As atuais condições de vida não só dificultam a ampliação das experiências motoras como também influenciam o desenvolvimento motor, os aspectos cognitivos e comportamentais das crianças (LOPES et al., 2011). Os jogos e brincadeiras são atividades importantes para o desenvolvimento integral e também para o processo de crescimento da criança, podendo facilitar o aprendizado de atividades mais complexas. No entanto, atualmente existe uma redução no brincar, o que leva a uma dificuldade na participação futura em atividades de exigência mais complexa, como o esporte (GRECO; SILVA, 2008).

Em uma das falas, nota-se que a professora percebe a importância de atividades direcionadas, com objetivos.

Porque, sem o projeto, quem fazia a Educação Física com os alunos éramos nós, mas às vezes é meio complicado porque tu queres usar os espaços e coincide o horário [...] às vezes a gente está lá trabalhando com os alunos e chegam os maiores, falta o professor deles. Ou se não eles pedem muito para ir pra pracinha, mas eu não acho muito válido, sei que o brincar é desenvolver várias motricidades, mas eu acredito que tenha que ser uma brincadeira que eles tenham foco naquilo ali [...] (PROFESSORA 1, 2018)

\section{Percepção das professoras do currículo sobre as expectativas pós-realização da IP do JPA}

De modo geral, as professoras afirmam que suas expectativas quanto à intervenção do JPA foram superadas. Foi realizada a seguinte pergunta: "O Projeto Jogando para Aprender atendeu às tuas expectativas? Se sim, como?". Quanto à importância da equipe de trabalho do projeto, descrevem assim:

\section{São pessoas que estão preparadas, gente que aproveita o curso que tá fa- zendo, eles gostam do que fazem, têm carinho pelas crianças, conseguiram conquistar as crianças. É muito difícil, olha, nem nós dentro da sala de aula às vezes conseguimos fazer o que eles fizeram em tão pouco tempo assim. (PROFESSORA 1, 2018) \\ E eles são ótimos né?, os professores do projeto, são muito bons, muito bon mesmo, eu vejo assim a maneira como eles lidam com as crianças, afetivida- de que eles têm com as crianças, ao mesmo tempo em que são firmes Eu acho eles muito bons... (PROFESSORA 2, 2018)}

As professoras reforçam a importância que os alunos deram à intervenção do JPA, pois para eles era o dia da EF, dia de saírem de suas salas de aula para algo diferente do habitual.

Foi perfeito, assim, acho que mais até do que a gente esperava, porque... eles adoram, é uma coisa que não tinham, não tenho vergonha porque não vou dizer que tinham, porque não tinham, o máximo que eu fazia era leva pro pátio, fazia algumas brincadeiras, mais leves, mas essa coisa de jogo, não, jogo de regras mesmo, não, e acho importante a colocação, então, fo muito bom, eu gostei bastante. Assim, e eles também, a gente percebe, eles ficam ansiosos todos... Cinco dias da semana, dizem: E hoje, hoje é? Tem dia de Educação Física, atividade física. (PROFESSORA 2, 2018)

Essa reação dos escolares vai ao encontro do planejamento do JPA, que buscou ensinar respeitando as fases de aprendizado das crianças, o que certamente colaborou para uma influência positiva na ampliação de vivências motoras. Com cuidado de que a IP favorecesse o ensino com o prazer da brincadeira, para que habilidades básicas como, por exemplo, a manipulação e locomoção fossem aperfeiçoadas em um processo divertido.
Conforme mencionado pelas professoras, o direcionamento que o projeto oferecia às individualidades dos escolares cooperou para estimular a motivação deles para a realização das aulas. Isso pode ser justificado devido à iniciação esportiva ter como característica respeitar as particularidades de cada indivíduo que está praticando, como as facilidades e dificuldades que apresentam durante a realização das atividades, o que muitas vezes é um grande desafio para os professores (LONGO et al., 2017).

\section{CONCLUSÃO}

Os resultados do estudo devem ser interpretados levando em consideração algumas limitações, por fazer referência a um contexto específico, no qual a Universidade se aproxima do ambiente escolar já existente, com suas particularidades e por um período determinado.

Ao analisarmos os resultados da segunda entrevista pudemos perceber que as informações permitiram traçar uma visão panorâmica e retrospectiva, a partir do olhar das professoras. Por consequência, notar que objetivos alcançados foram além das expectativas das professoras do currículo referentes ao JPA, no sentido da percepção da evolução dos alunos, os quais passaram a ser mais organizados, cooperativos e menos agressivos.

Sendo assim, destacamos que a investigação se mostrou uma importante ferramenta, tanto ao nortear a realização do JPA quanto no sentido de proporcionar valiosas informações pertinentes a futuras intervenções. Dessa forma, sugerimos que em situações semelhantes, principalmente em que as interferências são externas a comunidade escolar, que as professoras sejam consultadas, pois elas podem contribuir para que o processo de intervenção ocorra de forma mais eficaz.

\section{REFERÊNCIAS}

BARDIN, L. Análise de conteúdo. Lisboa: Edições 70, 2011.

BRANDÃO, L. C. Comunicação escola e família: uma intervenção com professores baseada na análise funcional do comportamento. 2016. 104f. Dissertação (Mestrado em Psicologia Clínica) - Universidade de São Paulo, São Paulo, 2016.

BRASIL. Lei $n^{\circ}$ 9.394, de 20 de dezembro de 1996. Estabelece as Diretrizes e Bases da Educação Nacional. Diário Oficial da República Federativa do Brasil, Poder Executivo, Brasília, DF, v. 134, n. 248, 23 dez. 1996. Seção 1. Disponível em: <http://portal.mec.gov.br/seesp/arquivos/pdf/lei9394_ldbn1. pdf $>$. Acessado em: 16 de março de 2020

BRASIL. Resolução no 7, de 14 de dezembro de 2010. Fixa as Diretrizes Curriculares Nacionais para o Ensino Fundamental de 9 (nove) anos. Brasília, DF, dez. 2010. Disponível em: <http://portal.mec.gov.br/index.php?option=com docman\&view=download\&alias $=7246-$ rceb007-10\&category slug $=-$ dezembro-2010-pdf\&Itemid=30192>. Acessado em: 13 de julho de 2020.

BROTTO, B. M.; ROSSETTO JÚNIOR, A. J. Estratégias de ensino do esporte educacional. São Paulo: Gráfica Paulo's, 2017.

DARIDO, S. C.; RANGEL, I. C. A. Educação física no ensino superior - educação física na escola: implicações para a prática pedagógica. Rio de Janeiro: Guanabara Koogan; 2005.

FREIRE, J. B. Educação de corpo inteiro. 2. ed. São Paulo: Scipione; 1991.

FREIRE, J. B. Educação de corpo inteiro: teoria e prática da educação física. São Paulo: Scipione; 1997.

GIL, A. C. Métodos e técnicas de pesquisa social. São Paulo: Atlas; 2008.

GRECO, P. J. Metodologia do ensino dos esportes coletivos: iniciação esportiva universal, aprendizado incidental-ensino intencional. Revista Mineira de Educação Física, Viçosa, v. 20, p. 145-74, 2012. 
GRECO, P. J.; BENDA, R. N. Da aprendizagem motora ao treinamento técnico - conceitos e perspectivas. In: GRECO, P. J. (Org.). Iniciação esportiva universal: metodologia da iniciação esportiva na escola e no clube. Belo Horizonte: UFMG, v. 2, 1998. p. 15-38.

GRECO, P. J.; BENDA, R. N.; RIBAS, J. Estrutura temporal. In: GRECO, P. J.; BENDA, R. N. Iniciação esportiva universal: da aprendizagem motora ao treinamento técnico. Belo horizonte: UFMG, 2007, p. 68.

GRECO, P. J.; SILVA, S. A. A metodologia do ensino dos esportes no marco do programa segundo tempo. In: OLIVEIRA, A. A. D.; PERIM, G. L. Fundamentos pedagógicos para o programa segundo tempo. Brasília: Ministério dos Esportes. Porto Alegre: UFRGS, 2008. p.163-206.

KANUL, F.; RAMÍREZ, M. Á. Family violence and child abuse in Latim America and the Caribbean: the cases off Colombia and Mexico. Washington: Inter-American Development Bank; 2005.

KRÖGER, C.; ROTH, K. Escola da bola: um ABC para iniciantes nos jogos esportivos. São Paulo: Phorte; 2002.

LE BOULCH, J. Educação psicomotora. Porto Alegre: Artes Médicas; 1987.

LONGO, R. A.; TERTULIANO, I. W.; SENA, A. B. D.; MORÃO, K. G.; VERZANI, R. H.; MACHADO, A. A. A permanência de crianças e jovens nos esportes: olhares para iniciação e especialização esportiva. Caderno de Educação Física e Esporte, Marechal Cândido Rondon, v. 15, n. 2, p. 121-32, 2017.

LOPES, L. O.; LOPES, V. P.; SANTOS R.; PEREIRA, B. O. Associações entre actividade física, habilidades e coordenação motora em crianças portuguesas. Revista Brasileira de Cineantropometria \& Desempenho Humano, Florianópolis, v. 13, n. 1, p. 15-21, 2011.

MOLINA NETO, V.; TRIVIÑOS, A. N. S. A pesquisa qualitativa na educação física: alternativas metodológicas. 4. ed. Porto Alegre: Sulina, 2017.

NORA, D. D.; SAWITZKI, R. L. A educação física nos anos iniciais com professores unidocentes. Cadernos de Formação RBCE, Rio de Janeiro, v. 5, n. 1, p. 68-79, mar. 2014.

PIAGET, J. O juízo moral na criança. São Paulo: Summus, 1994.

PINHEIRO, E. S.; Da SILVA, P. R. L.; RIBEIRO, F. S.; SILVA, F. F. G.; BOTELHO, V. H. Jogando para aprender. In: MICHELON, F. F.; BANDEIRA, A. R. (Orgs.). A extensão universitária nos $\mathbf{5 0}$ anos da Universidade Federal de Pelotas. Pelotas: UfPel, 2020. p. 474-82.

PINHEIRO, E. S.; SILVA, P. M.; Da SILVA, P. R. L.; BOTELHO, V. H. Projeto de Extensão Jogando para Aprender: possibilidades do ensino das capacidades coordenativas e táticas básicas para escolares. Revista da Extensão da UFRGS, Porto Alegre, n. 17, p. 26-34, 2018.

SALLES, L. M. F.; DE PAULA E SILVA, J. M. A.; CASTRO, J. C. R.; VILLANUEVA C. F. Um estudo sobre jovens e violência no espaço escolar. Psicologia \& Sociedade, Belo Horizonte, v. 26, n. 1, p 148-57, 2014.

SEITSINGER, A. M.; FELNER, R. D.; BRAND, S.; BURNS, A. A large-scale examination of the nature and efficacy of teachers' practices to engage parents: assessment, parental contact, and student-level impact. Journal of School Psychology, Novi Sad, v. 46, p. 477-505, 2008

TANI, G.; MANOEL, E. J.; KOKUBUN, E.; PROENÇA, J. E. Educação física escolar: fundamentos de uma abordagem desenvolvimentista. São Paulo: EPU, 1988.

TRIVIÑOS, A. N. S. Introdução à pesquisa em ciências sociais: a pesquisa qualitativa em Educação. 4. ed. São Paulo: Atlas, 1995.

VIANA-MEIRELES, L. G.; SALDANHA, D. M. F.; MENESCAL, D. M. P.; OLIVEIRA, R. K. A.; GONZALEZ, R. H. Projetos esportivos sociais para adolescentes no Brasil: impactos, implicações e barreiras. Caderno de Educação Física e Esporte, Marechal Cândido Rondon, v. 18, n. 1, p. 77-82, 2020.

VOSER, R. C.; GIUSTI, J. G. M.; AZEVEDO JÚNIOR, M. R. Futsal: ensino através dos jogos de inteligência e capacidade tática. Canoas: ULBRA, 2016.

\section{AGRADECIMENTOS}

Os autores agradecem a participação das professoras participantes.

\section{CONFLITO DE INTERESSE}

Os autores do estudo declaram não haver conflito de interesses

\section{ORCID E E-MAIL DOS AUTORES}

Patrícia da Rosa Louzada da Silva (Autora Correspondente) ORCID: 0000-0002-0259-299X.

E-mail: patricia_prls@hotmail.com

Patricia Machado da Silva

ORCID: 0000-0002-3336-9993.

E-mail: patriciamachadodasilva@hotmail.com

Vivian Hernandez Botelho

ORCID: 0000-0001-9523-2565.

E-mail: vivianhbotelho@gmail.com

Franciéle da Silva Ribeiro

ORCID: 0000-0002-0027-3354.

E-mail: frandasilva9@yahoo.com.br

Eraldo dos Santos Pinheiro

ORCID: 0000-0002-5749-1512.

E-mail: esppoa@gmail.com

\section{FINANCIAMENTO}

Este estudo não teve apoio financeiro. 